\title{
Age-dependent effects of homocysteine and dimethylarginines on cardiovascular mortality in claudicant patients with lower extremity arterial disease
}

\author{
Philipp Jud ${ }^{1}$ (D) . Franz Hafner ${ }^{1} \cdot$ Nicolas Verheyen $^{2} \cdot$ Thomas Gary $^{1} \cdot$ Andreas Meinitzer $^{3} \cdot$ Marianne Brodmann $^{1}$. \\ Gerald Seinost $^{1} \cdot$ Gerald Hackl $^{1}$
}

Received: 9 March 2018 / Accepted: 15 June 2018 / Published online: 26 June 2018

(c) The Author(s) 2018

\begin{abstract}
The association among serum homocysteine (HCY), symmetric dimethylarginine (SDMA), and asymmetric dimethylarginine (ADMA) is of interest in endothelial dysfunction, although the underlying pathology is not fully elucidated. We investigated the relationship of HCY with SDMA and ADMA regarding their long-time outcome and the age dependency of HCY, SDMA, and ADMA values in claudicant patients with lower extremity arterial disease. 120 patients were included in a prospective observational study (observation time $7.96 \pm 1.3$ years) with cardiovascular mortality as the main outcome parameter. Patients with intermittent claudication prior to their first endovascular procedure were included. HCY, SDMA, and ADMA were measured by high-performance liquid chromatography. Cutoff values for HCY $(\leq />15 \mu \mathrm{mol} / \mathrm{l})$, SDMA $(\leq />0.75 \mu \mathrm{mol} / \mathrm{l})$, and ADMA $(\leq />0.8 \mu \mathrm{mol} / \mathrm{l})$ differed significantly regarding cardiovascular mortality $(p<0.001, p<0.001$, $p=0.017$, respectively). Age correlated significantly with HCY $(r=0.393 ; p<0.001)$, SDMA $(r=0.363 ; p<0.001)$, and ADMA $(r=0.210 ; p=0.021)$. HCY and SDMA $(r=0.295 ; p=0.001)$ as well as SDMA and ADMA $(r=0.380 ; p<0.001)$ correlated with each other, while HCY and ADMA did not correlate $(r=0.139 ; p=0.130)$. Patients older than 65 years had higher values of HCY $(p<0.001)$ and SDMA $(p=0.01)$, but not of ADMA $(p=0.133)$. In multivariable linear regression, age was the only significant independent risk factor for cardiovascular death (beta coefficient 0.413 ; 95\% CI 0.007-0.028; $p=0.001$ ). Age correlated significantly with HCY, SDMA, and ADMA. However, only age was an independent predictor for cardiovascular death. Older patients have higher values of HCY and SDMA than younger subjects suggesting age-adjusted cutoff values of HCY and SDMA due to strong age dependency.
\end{abstract}

Keywords Peripheral arterial disease $\cdot$ Homocysteine $\cdot$ Aging $\cdot$ Intermittent claudication

$\begin{array}{ll}\text { Abbreviations } \\ \text { ADMA } & \text { Asymmetric dimethylarginine } \\ \text { CV } & \text { Cardiovascular } \\ \text { eGFR } & \text { Estimated glomerular filtration rate } \\ \text { eNOS } & \text { Endothelial NO synthase } \\ \text { HCY } & \text { Homocysteine }\end{array}$

Philipp Jud

philipp.jud@medunigraz.at

1 Division of Angiology, Department of Internal Medicine, Medical University Graz, Auenbruggerplatz 15, 8036 Graz, Austria

2 Division of Cardiology, Department of Internal Medicine, Medical University Graz, Graz, Austria

3 Institute of Medical and Chemical Laboratory Diagnostics, Medical University Graz, Graz, Austria

$\begin{array}{ll}\text { LEAD } & \text { Lower extremity arterial disease } \\ \text { NO } & \text { Nitric oxide } \\ \text { ROC } & \text { Receiver operating curve } \\ \text { ROS } & \text { Reactive oxygen species } \\ \text { SDMA } & \text { Symmetric dimethylarginine }\end{array}$

\section{Introduction}

Lower extremity arterial disease (LEAD) refers to atherosclerotic stenosis or occlusions of the arteries of the lower extremities, which is a disease occurring preferentially in elderly persons. The presence of LEAD might be an indicator of generalized atherosclerosis and therefore poses a significantly increased risk for potentially fatal cardiovascular (CV) events [1]. Known susceptible risk factors are arterial hypertension, hypercholesterolemia, diabetes, and smoking, 
while the most non-susceptible risk factors are sex and age. Furthermore, there is a known association of these risk factors with endothelial dysfunction due to decreased release of endothelium-derived nitric oxide (NO). Endothelial dysfunction is an independent risk factor of $\mathrm{CV}$ morbidity and mortality [2].

The potential role of homocysteine (HCY) in the pathogenesis of $\mathrm{CV}$ diseases has been postulated by McCully in 1969. He observed that patients suffering from rare gene defects which led to elevated HCY levels suffered from premature atherosclerosis as early as in their second or third decade of life [3]. At the beginning of the 1990s, the association of HCY and LEAD was more strongly emphasized than the one of HCY and coronary artery disease [4]. By now, the influence of $\mathrm{HCY}$ on endothelial function has been thoroughly researched, although the underlying pathology not of the HCY-dependent endothelial dysfunction has not been completely explained yet.

In this context, the association of HCY with symmetric dimethylarginine (SDMA) and asymmetric dimethylarginine (ADMA) is particularly of interest. Contrary to ADMA which directly inhibits the endothelial NO synthase (eNOS), SDMA competes with the intracellular absorption of the NO precursor arginine. This process results in an indirectly decreased NO production via an intracellular deficiency of arginine [5] Both ADMA and SDMA might be directly associated with the occurrence of $\mathrm{CV}$ events [6]. HCY is seen as an independent CV biorisk factor as well, although it is unclear whether HCY itself leads to endothelial dysfunction. On one hand, a reduced endothelial-dependent NO liberation due to direct toxic effects on the endothelial cells as well as an inactivation of NO due to increased reactive oxygen species (ROS) production is assumed [7]. On the other hand, there is an assumption that SDMA and ADMA result in an inhibition of eNOS after their activation via $\mathrm{HCY}$ and cause an HCY-dependent endothelial dysfunction in this way [8, 9].

The aim of the present study was to investigate the relationship between HCY, SDMA as well as ADMA in claudicant patients with LEAD regarding their long-term prognoses. As HCY metabolism clearly changes with aging, we investigated the age dependency of this relationship in claudicant patients [10-12].

\section{Materials and methods}

\section{Study design and patient collective}

Between March 2002 and November 2004, a total of 120 consecutive patients were included in a prospective observational study with $\mathrm{CV}$-related death as principal outcome parameter. The study included patients who presented at the outpatient clinic of the Division of Angiology in the Medical University of Graz because of intermittent claudication (Rutherford classification stage 2-3) and who had to undergo their first endovascular procedure of the pelvic and/ or femoropopliteal arteries due to a significant hemodynamic lesion in the respective arteries despite antiplatelet therapy. All patients were on antiplatelet therapy prior to endovascular intervention with either acetylsalicylic acid $100 \mathrm{mg}$ or clopidogrel $75 \mathrm{mg}$ per day. All patients underwent prior unsupervised exercise therapy, while none of the patients took folate or vitamin B12 supplements due to the influence of both vitamins on HCY metabolism. The patients' dietary intake was in accordance with an average Middle European diet. Antegrade or retrograde access via the common femoral artery was used in all interventions. Patients suffering from LEAD below the knee objectified by Doppler ultrasound of the arteries or magnetic resonance angiography were not included in the study, as intermittent claudication (Rutherford classification stage 2-3) is not an indication for endovascular recanalization in patients with LEAD below the knee [13]. The occurrences of a fatal stroke or fatal myocardial infarction were defined as CV death. Patients who were suffering from unstable angina pectoris or consequences of a stroke at the time of recruitment were excluded from our study. Other exclusion criteria were uncontrolled arterial hypertension (defined as a blood pressure above $180 / 120 \mathrm{mmHg}$ at the time of study inclusion after $10 \mathrm{~min}$ in resting position), decompensated heart failure, life expectancy of less than a year, wound infections, vegetarians or vegans, and contraindications against anticoagulants and/or antiplatelet agents. All patients gave their written informed consent after being accurately informed about the clinical trial. The study was approved by the Institutional Review Board of the Medical University Graz, Austria (EK 23-038 ex 10/11).

\section{Data collection}

On the day of the endovascular intervention, the patients' baseline characteristics were determined. Subsequently, a total of four follow-up visits after 1, 3, 6 and 12 months were scheduled. At each study visit, the patients' concomitant medication and the occurrence of $\mathrm{CV}$ events were recorded. The final examination was conducted between October 2010 and May 2011. During the final examination, the occurrence of $\mathrm{CV}$ events was recrded. For this purpose, patients were invited to an outpatient examination/survey, in which they answered questions about their LEAD symptoms, medical history, and current medication. Using the same survey, patients who could not participate in the examination were interviewed on the telephone as an alternative means of data collection. If patients were deceased or not reachable by telephone, the primary care physician of the respective patients 
was contacted and informed about the study. This enabled the collection of the necessary data regarding mortality and the occurrence of CV events (CV death, stroke, myocardial infarction) as well as current medication. Finally, all medical files in all public Styrian hospitals including their emergency rooms and divisions of pathology were reviewed to complete data collection.

\section{Biochemical analyses}

At the baseline visit, fasting blood samples were obtained. The serum was centrifuged and stored at $-70{ }^{\circ} \mathrm{C}$ until further analysis of HCY, SDMA, and ADMA was performed in March 2011 by means of high-performance liquid chromatography with a solid phase extraction and precolumn derivatization technique which was first described by Teerlink with only minor modifications $[14,15]$. According to previous reports, the investigated biomarkers can be assumed as stable [16]. Within-day coefficients of variation for SDMA were $4.6 \%(0.60 \mu \mathrm{mol} / \mathrm{L})$ and $1.9 \%(1.0 \mu \mathrm{mol} / \mathrm{L})$, and between-day coefficients of variance were $9.8 \%$ $(0.60 \mu \mathrm{mol} / \mathrm{L})$ and $6.1 \%(1.0 \mu \mathrm{mol} / \mathrm{L})$. Within-day coefficients of variation for ADMA were $3.1 \%(0.62 \mu \mathrm{mol} / \mathrm{L})$ and $1.0 \%(2.0 \mu \mathrm{mol} / \mathrm{L})$, and between-day coefficients of variance were $9.0 \%(0.62 \mu \mathrm{mol} / \mathrm{L})$ and $2.2 \%(2.0 \mu \mathrm{mol} / \mathrm{L})$.

\section{Statistics}

In case of continuous variables, patient characteristics were given as means ( \pm standard deviation). Median and interquartile range were used to express skewed data. Categorical variables were represented by frequency and percentages. The normal distribution was examined via Kolmogorov-Smirnov and Shapiro-Wilk test. The twosided $t$ test was used for the comparison of groups in case of parametrical distribution. For non-parametrical data, a Mann-Whitney $U$ test was utilized. Using a $\chi^{2}$ and Fisher's exact test, qualitative command variables were compared. Optimal cutoff values for HCY, SDMA, and ADMA as potential predictors of subsequent cardiovascular death were evaluated by receiver operating curve (ROC) analyses. We applied log-rank statistics and assessed survival analysis utilizing Kaplan-Meier curves. The Jonckheere-Terpstra test was used for trend statistics. Correlations between metrical variables were expressed by Pearson's correlation coefficients. Variables were also assessed as predictors of all-cause mortality in multivariate cox proportional regression analyses. We assumed statistical significance when $P$ value was $<0.05$. Statistical analyses were executed via SPSS version 20.0.

To assess the age dependency of concentrations of HCY, ADMA, and SDMA, the cohort was split by age of 65 years because the conventional age threshold at which people can be assumed to be "old" is commonly 65 years. Betweengroup differences were assessed using analysis of variance.

\section{Results}

A total of 120 patients were included in the analysis. Cardiovascular deaths were recorded during a mean follow-up of $7.96( \pm 1.3)$ years. Patients ${ }^{\prime}$ baseline characteristics are shown in Table 1.

At the beginning of our analysis, age was divided into tertiles (first tertile: $54.93 \pm 6.39$ [95\% CI 52.96-56.90] years; second tertile: $67.53 \pm 2.90$ [95\% CI 66.57-68.48] years; third tertile: $78.23 \pm 3.22$ [95\% CI 77.19-79.27] years). These tertiles were compared with respect to $\mathrm{CV}$ death. As expected, a significant difference between the three groups was observed (Fig. 1). Subsequently, the optimal cutoff value for HCY, SDMA, and ADMA between surviving and deceased patients was determined utilizing ROC curves. The value of $\mathrm{HCY}$ was $15 \mu \mathrm{mol} / 1$, the one of SDMA $0.75 \mu \mathrm{mol} / \mathrm{l}$, and the one of ADMA $0.8 \mu \mathrm{mol} / \mathrm{l}$ (Table 2).

In the next step, the groups were compared with the established cutoff values. Age was significantly different for all three variables (HCY $p<0.001$, SDMA $p<0.001$, $\mathrm{ADMA}=0.017$, respectively) (Table 3 ).

During the observation period, in the HCY group $\leq 15 \mu \mathrm{mol} / 111 / 66$ patients $(16.3 \%)$, and in the HCY group $>15 \mu \mathrm{mol} / 121 / 54$ patients $(38.9 \%)$ died as a result of $\mathrm{CV}$ disease $(p=0.007)$. Furthermore, survival from $\mathrm{CV}$ disease was significantly shorter in the group with $\mathrm{HCY} \leq 15 \mu \mathrm{mol} / \mathrm{l}$ as compared to the one with $\mathrm{HCY}>15 \mu \mathrm{mol} / 1 \quad(109.5 \pm 3.0$ months [95\% CI $103.5-115.4]$ vs. $88.9 \pm 4.9$ months [95\% CI 79.4-98.4]; log-rank test $p=0.005$ ). In the group with SDMA $\leq 0.75 \mu \mathrm{mol} / 113 / 73$ patients $(17.8 \%)$ and in the group with SDMA $>0.75 \mu \mathrm{mol} / 119 / 47$ patients $(40.4 \%)$ died as a consequence of CV disease $(p=0.010)$. The mean survival duration of a patient with $\mathrm{CV}$ disease was significantly different between the two SDMA groups, as well (SDMA $\leq 0.75 \mu \mathrm{mol} / 1: 104.3 \pm 3.1$ months [95\% CI 98.2-110.3]; SDMA $>0.75 \mu \mathrm{mol} / 1$ 92.0 \pm 5.4 months [95\% CI 81.4-102.6]; log-rank test $p=0.006$ ). Similar observations could be made in case of ADMA. In the group with ADMA $\leq 0.8 \mu \mathrm{mol} / 120 / 99$ patients $(20.2 \%)$, and in the group with ADMA $>0.8 \mu \mathrm{mol} / 1$ 12/21 patients (57.1\%) died as a result of CV disease $(p=0.002)$. The mean survival duration was also significantly different in case of ADMA (ADMA $\leq 0.8 \mu \mathrm{mol} / \mathrm{l}: 106.4 \pm 2.9$ months $[95 \% \mathrm{CI}$ 100.8-112.0]; ADMA $>0.8 \mu \mathrm{mol} / 1 \mathrm{l} 73.0 \pm 7.4$ months [95\% CI 58.4-87.5]; log-rank test $p<0.001$ ) (Table 4, Fig. 2).

As a next step, the variables age, estimated glomerular filtration rate (eGFR), HCY, SDMA, and ADMA were analyzed in their metric forms regarding their associations 
Table 1 Patients' characteristics

\begin{tabular}{|c|c|}
\hline$N$ & 120 \\
\hline Men, $n(\%)$ & $84(70.0)$ \\
\hline Age $(y)$, mean $( \pm$ standard derivation $)$ & $66.5( \pm 10.7)$ \\
\hline BMI in $\mathrm{kg} / \mathrm{m}^{2}$, mean $( \pm$ standard derivation $)$ & $26.7( \pm 3.2)$ \\
\hline Observation time in years, mean ( \pm standard derivation) & $7.96( \pm 1.3)$ \\
\hline \multicolumn{2}{|l|}{ Previous history, $n(\%)$} \\
\hline Myocardial infarction & $11(9.3)$ \\
\hline Cerebrovascular disease (stroke, TIA) & $8(6.8)$ \\
\hline Diabetes mellitus & $38(31.7)$ \\
\hline Arterial hypertension & $94(78.3)$ \\
\hline Smoking & $77(73.3)$ \\
\hline Current & $48(40.0)$ \\
\hline Ex & $42(35.0)$ \\
\hline Hypercholesterolemia & $60(50.0)$ \\
\hline \multicolumn{2}{|l|}{ Kidney function } \\
\hline eGFR, $\mathrm{ml} / \mathrm{min}^{-1} 1.73 \mathrm{~m}^{-2}$, mean $( \pm$ standard derivation $)$ & $68.3( \pm 24.6)$ \\
\hline Creatinine, mg/dl, median (25th-75th percentile) & $1.2(1.0-1.3)$ \\
\hline ABI, median (25th-75th percentile) & $0.70(0.57-0.89)$ \\
\hline \multicolumn{2}{|l|}{ Interventional procedure, $n(\%)$} \\
\hline PTA & $98(81.7)$ \\
\hline PTA + stent & $22(18.3)$ \\
\hline \multicolumn{2}{|l|}{ Drug therapies at discharge, $n(\%)$} \\
\hline Antiplatelet agents & $102(85.0)$ \\
\hline Beta-blockers & $37(30.8)$ \\
\hline ACE inhibitors or ARBs & $71(59.1)$ \\
\hline Statins & $55(45.8)$ \\
\hline Hemoglobin in $\mathrm{g} / \mathrm{dl}$, mean ( \pm standard derivation) & $13.9( \pm 1.6)$ \\
\hline Platelets in G/l, mean ( \pm standard derivation) & $235( \pm 59)$ \\
\hline hs-CRP in mg/l, median (25th-75th percentile) & $4.0(2.1-7.3)$ \\
\hline Homocysteine in $\mu \mathrm{mol} / \mathrm{L}$, median (25th-75th percentile) & $14.7(12.1-17.5)$ \\
\hline \multicolumn{2}{|l|}{ Lipids in mg/dl, median (25th-75th percentile) } \\
\hline LDL & $120(93-143)$ \\
\hline HDL & $47(40-59)$ \\
\hline Triglycerides & $150(105-206)$ \\
\hline Lipoprotein (a) & $12.5(9.5-42.0)$ \\
\hline $\mathrm{HbA1c}$ in $\%$, median (25th-75th percentile) & $5.7(5.4-6.4)$ \\
\hline
\end{tabular}

$B M I$ body mass index, TIA transient ischemic attack, $e G F R$ estimated glomerular filtration rate, $A B I$ anklebrachial index, $P T A$ percutaneous transluminal angioplasty, $A C E$ inhibitors angiotensin-converting enzyme inhibitors, $A R B$ angiotensin-receptor blockers, $h s-C R P$ high-sensitive C-reactive protein, $L D L$ low-density lipoproteins, $H D L$ high-density lipoproteins, $H b A 1 c$ hemoglobin A1c

among each other via Pearson's correlations. Thereby, the variable age correlated significantly with $\mathrm{HCY}(r=0.393$; $p<0.001)$ as well as SDMA $(r=0.363 ; p<0.001)$ and ADMA $(r=0.210 ; p=0.02)$. A significant correlation was also observed between HCY and SDMA $(r=0.295$; $p=0.001)$ as well as SDMA and ADMA $(r=0.380$; $p<0.001)$. HCY and ADMA had no significant correlation $(r=0.139 ; p=0.130)$ (Fig. 3$)$.

Due to this age correlation, we analyzed the age dependency of HCY, SDMA, and ADMA concentrations by splitting the cohort into two subgroups. In subjects aged below
65 years ( $n=54$, mean age $56.8 \pm 6.79$ years $)$, the concentrations of HCY and SDMA were significantly lower than in those over 65 years ( $n=66$, mean age $74.44 \pm 5.37$ years) with median HCY $12.9 \mu \mathrm{mol} / \mathrm{l}$ (interquartile range 10.2-15.1) vs. $16.4 \mu \mathrm{mol} / \mathrm{l}(13.1-20.1)(p<0.001)$ and median SDMA $0.63 \mu \mathrm{mol} / 1(0.58-0.73)$ vs. $0.76 \mu \mathrm{mol} / 1$ $(0.65-0.96)(p=0.01)$. There was no significant difference in ADMA regarding this age cutoff with median ADMA $0.71 \mu \mathrm{mol} / 1$ (0.66-0.76) vs. $0.73 \mu \mathrm{mol} / 1$ (0.67-0.77) $(p=0.133)$ (Fig. 4). 


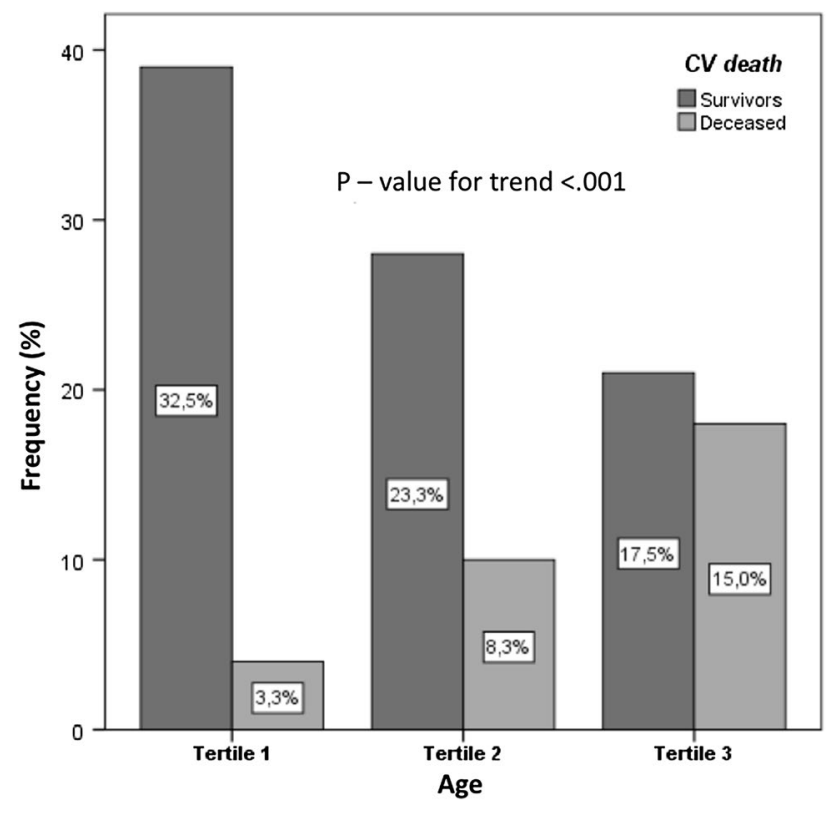

Fig. 1 Tertiles of age stratified with cardiovascular death

Finally, in adjusted cox proportional regression analyses including the variables age, eGFR, HCY, SDMA, and ADMA, age was independently predictive of all-cause death, when comparing the highest with the lowest tertile (HR with 95\% confidence interval: $5.140(1.191-22.187), p=0.028)$.

\section{Discussion}

HCY is a chemical intermediate for the metabolism of sulfurous amino acids. In case of a reaction between methionine and adenosine triphosphate, HCY is created after methylation. Methionine is supplied by the intake of food, in particular by animal products such as meat and cheese. Usually, HCY is remethylized into methionine with the help of enzymes, or metabolized into cysteine and glutathione [17]. A great variety of factors for the development of hyperhomocysteinemia have been discussed. Next to genetic enzyme defects in HCY metabolism, hyperhomocysteinemia is also in inverse correlation to the vitamin status of folic acid, vitamin B6, and vitamin B12. Chronic alcohol consumption and gastrointestinal pathologies with impaired absorption and malnutrition can lead to hyperhomocysteinemia as a result of functional deficiencies. High coffee intake was also associated with elevated HCY levels [18]. Conversely, inhibition of the proliferation of smooth muscle cells as well as a reduction of endothelial cell destruction as a result of lowering HCY levels, for instance via folic acid substitution, were reported [19, 20]. Numerous studies have determined $\mathrm{HCY}$ as independent cardiovascular biorisk factor. The most significant role in this context seems to be played by primarily the HCY-dependent endothelial dysfunction [21]. It is, however, unclear whether HCY directly leads to endothelial dysfunction, or if the HCY-activated dimethylarginines are responsible for it. The present study could prove a significant correlation between HCY and SDMA, but not between HCY and ADMA. On the other hand, the dimethylarginines SDMA and ADMA were significantly correlated to each other. Therefore, an HCY-dependent endothelial dysfunction via dimethylarginines appears at least partially plausible. Other data support the result of our study because dimethylarginines have already been attributed with a certain quantification of the HCY-dependent endothelial dysfunction [8, 9]. The HCY-dependent endothelial dysfunction seems to be a multifactorial process, nonetheless.

SDMA as structural isomer of ADMA is eliminated by the kidneys and was considered to be biochemically inactive. SDMA does not only seem to correlate with renal function, but also appears to have a close relationship with the expression of atherosclerotic lesions. Therefore, SDMA is also considered as an independent factor associated with the occurrence of cardiovascular end points such as stroke, myocardial infarction, and CV death [22, 23]. Furthermore, data that associated SDMA more strongly with CV events than ADMA have been published [24]. The most plausible underlying pathology not in this context seems to be the influence of SDMA on the store-operated calcium channels located on the endothelial cells after activation by HCY, as an activation of these channels by SDMA results in an increase of oxidative stress [8]. The effects of oxidative stress consequently lead to an increase in the expression of redox-sensitive genes which constitutes a deciding step of early atherogenesis $[25,26]$.
Table 2 ROC analyses evaluating cutoff values for HCY, SDMA, and ADMA

\begin{tabular}{lllllll}
\hline Variable & Area \pm SE & Asympt. Sign. & $95 \%$ CI & $\begin{array}{l}\text { Cutoff value } \\
(\mu \mathrm{mol} / \mathrm{l})\end{array}$ & Sensitivity & Specificity \\
\hline HCY & $0.637 \pm 0.059$ & $\mathbf{0 . 0 2 2}$ & $0.522-0.751$ & 15 & 0.656 & 0.602 \\
SDMA & $0.670 \pm 0.060$ & $\mathbf{0 . 0 0 5}$ & $0.553-0.787$ & 0.75 & 0.594 & 0.682 \\
ADMA & $0.632 \pm 0.061$ & $\mathbf{0 . 0 2 8}$ & $0.512-0.752$ & 0.8 & 0.375 & 0.898 \\
\hline
\end{tabular}

$p$ values $<0.05$ are shown in bold

$H C Y$ homocysteine, SDMA symmetric dimethylarginine, ADMA asymmetric dimethylarginine 
Table 3 Comparison of population with

$\mathrm{HCY} \leq />15 \mu \mathrm{mol} / \mathrm{l}$, SDMA $\leq />0.75 \mu \mathrm{mol} / \mathrm{l}$ and $\mathrm{ADMA} \leq />0.8 \mu \mathrm{mol} / \mathrm{l}$

\begin{tabular}{|c|c|c|c|}
\hline \multicolumn{3}{|l|}{ Variable } & \multirow[t]{2}{*}{$P$ value } \\
\hline & $\mathrm{HCY} \leq 15 \mu \mathrm{mol} / 1$ & $\mathrm{HCY}>15 \mu \mathrm{mol} / 1$ & \\
\hline Men, $n(\%)$ & $47(39.2)$ & $37(30.8)$ & 0.842 \\
\hline Age (y) & $63.2( \pm 10.0)$ & $70.5( \pm 10.2)$ & $<0.001$ \\
\hline BMI $\left(\mathrm{kg} / \mathrm{m}^{2}\right)$ & $27.0( \pm 3.0)$ & $26.4( \pm 3.4)$ & 0.354 \\
\hline eGFR $\left(\mathrm{ml} / \mathrm{min}^{-1} 1.73 \mathrm{~m}^{-2}\right)$ & $76.1( \pm 23.3)$ & $58.8( \pm 22.8)$ & $<0.001$ \\
\hline $\mathrm{ABI}$ & $0.72( \pm 0.26)$ & $0.68( \pm 0.41)$ & 0.398 \\
\hline Hemoglobin (g/dl) & $14.3( \pm 1.4)$ & $13.4( \pm 1.8)$ & 0.002 \\
\hline Platelets (G/l) & $226.9( \pm 47.0)$ & $239.9( \pm 71.2)$ & 0.253 \\
\hline $\mathrm{CRP}(\mathrm{mg} / \mathrm{l})$ & $4.5( \pm 3.1)$ & $4.4( \pm 3.2)$ & 0.491 \\
\hline Total cholesterol (mg/dl) & $210.7( \pm 44.0)$ & $199.6( \pm 51.1)$ & 0.203 \\
\hline $\mathrm{LDL}(\mathrm{mg} / \mathrm{dl})$ & $127.1( \pm 35.6)$ & $111.5( \pm 41.5)$ & $\mathbf{0 . 0 3 0}$ \\
\hline HDL (mg/dl) & $48.0( \pm 19.5)$ & $45.0( \pm 20.0)$ & 0.329 \\
\hline Triglycerides (mg/dl) & $166( \pm 10)$ & $174( \pm 14)$ & 0.738 \\
\hline \multirow[t]{2}{*}{ HbA1c (\%) } & $5.7( \pm 0.9)$ & $5.7( \pm 1.1)$ & 0.734 \\
\hline & $\mathrm{SDMA} \leq 0.75 \mu \mathrm{mol} / \mathrm{l}$ & $\mathrm{SDMA}>0.75 \mu \mathrm{mol} / \mathrm{l}$ & \\
\hline Men, $n(\%)$ & $52(61.9)$ & $32(38.1)$ & 0.839 \\
\hline Age (y) & $63.5( \pm 10.4)$ & $71.2( \pm 9.5)$ & $<0.001$ \\
\hline BMI $(\mathrm{kg} / \mathrm{m} 2)$ & $26.9( \pm 3.2)$ & $26.4( \pm 3.1)$ & 0.423 \\
\hline $\mathrm{eGFR}\left(\mathrm{ml} / \mathrm{min}^{-1} 1.73 \mathrm{~m}^{-2}\right)$ & $75.9( \pm 25.2)$ & $56.4( \pm 18.1)$ & $<0.001$ \\
\hline $\mathrm{ABI}$ & $0.69( \pm 0.36)$ & $0.79( \pm 0.39)$ & 0.544 \\
\hline Hemoglobin (g/dl) & $14.1( \pm 1.6)$ & $13.5( \pm 1.7)$ & 0.061 \\
\hline Platelets (G/l) & $239.1( \pm 63.9)$ & $223.0( \pm 50.3)$ & 0.146 \\
\hline $\mathrm{CRP}(\mathrm{mg} / \mathrm{l})$ & $4.4( \pm 3.0)$ & $4.5( \pm 3.4)$ & 0.496 \\
\hline Total cholesterol (mg/dl) & $208.2( \pm 45.5)$ & $201.9( \pm 50.6)$ & 0.479 \\
\hline LDL (mg/dl) & $125.5( \pm 41.1)$ & $111.5( \pm 34.4)$ & 0.058 \\
\hline HDL (mg/dl) & $49.0( \pm 20.0)$ & $44.5( \pm 17.8)$ & 0.946 \\
\hline Triglycerides (mg/dl) & $170( \pm 10)$ & $168( \pm 15)$ & 0.780 \\
\hline \multirow[t]{2}{*}{$\mathrm{HbA1c}(\%)$} & $5.7( \pm 1.0)$ & $5.8( \pm 0.9)$ & 0.281 \\
\hline & $\mathrm{ADMA} \leq 0.8 \mu \mathrm{mol} / 1$ & ADMA $>0.8 \mu \mathrm{mol} / 1$ & \\
\hline Men, $n(\%)$ & $72(85.7)$ & $12(14.3)$ & 0.192 \\
\hline Age (y) & $65.4( \pm 10.6)$ & $71.5( \pm 10.0)$ & 0.017 \\
\hline BMI $(\mathrm{kg} / \mathrm{m} 2)$ & $26.9( \pm 3.1)$ & $26.0( \pm 3.3)$ & 0.276 \\
\hline eGFR $\left(\mathrm{ml} / \mathrm{min}^{-1} 1.73 \mathrm{~m}^{-2}\right)$ & $70.1( \pm 24.1)$ & $59.7( \pm 25.6)$ & 0.076 \\
\hline $\mathrm{ABI}$ & $0.71( \pm 0.30)$ & $0.73( \pm 0.43)$ & 0.736 \\
\hline Hemoglobin (g/dl) & $14.0( \pm 1.6)$ & $13.2( \pm 1.5)$ & 0.027 \\
\hline Platelets (G/1) & $232.4( \pm 52.9)$ & $234.4( \pm 84.5)$ & 0.888 \\
\hline CRP (mg/l) & $4.3( \pm 3.1)$ & $5.3( \pm 3.5)$ & 0.056 \\
\hline Total cholesterol (mg/dl) & $208.3( \pm 43.4)$ & $193.5( \pm 63.0)$ & 0.195 \\
\hline LDL (mg/dl) & $122.9( \pm 36.0)$ & $105.9( \pm 49.9)$ & 0.076 \\
\hline HDL (mg/dl) & $48.0( \pm 19.5)$ & $45.0( \pm 23.0)$ & 0.415 \\
\hline Triglycerides (mg/dl) & $168( \pm 10)$ & $177( \pm 14)$ & 0.165 \\
\hline HbA1c (\%) & $5.7( \pm 0.9)$ & $5.8( \pm 1.2)$ & 0.593 \\
\hline
\end{tabular}

We could neither observe a significant association between HCY and ADMA nor a significant difference in ADMA values between older and younger patients, although older claudicant patients have significantly higher values of HCY $(p<0.001)$ and SDMA $(p=0.01)$ than younger patients. A possible explanation for these findings could potentially be found in the form of the enzyme dimethylarginine dimethylaminohydrolase which does not influence 
Table 4 Multivariable linear regression model for CV death

\begin{tabular}{llrl}
\hline Risk factor & Beta coefficient & \multicolumn{1}{l}{$95 \%$ CI } & $P$ value \\
\hline Age & 0.413 & $0.007-0.028$ & $\mathbf{0 . 0 0 1}$ \\
eGFR & 0.223 & $-0.001-0.009$ & 0.088 \\
SDMA & 0.188 & $-0.015-0.602$ & 0.062 \\
ADMA & 0.158 & $-0.081-1.235$ & 0.085 \\
HCY & 0.012 & $-0.016-0.018$ & 0.894 \\
\hline
\end{tabular}

$p$ value $<0.05$ is shown in bold

$e G F R$ estimated glomerular filtration rate, SDMA symmetric dimethylarginine, $A D M A$ asymmetric dimethylarginine, $H C Y$ homocysteine

SDMA at all [27]. Dimethylarginine dimethylaminohydrolase is primarily responsible for an HCY-induced inhibition of the ADMA/eNOS/NO pathway in endothelial cells, but does not exhibit any significant changes with increasing age and in the presence of ischemia in particular [28, 29].

As outlined above, the present study significantly associated HCY, SDMA, and ADMA with the occurrence of $\mathrm{CV}$ death. After correction of the variables in a logistic regression model, the variable age was identified as the only significant risk factor and age correlated significantly with HCY, SDMA, and ADMA ( $r=0.393 ; r=0.363 ; r=0.210$, respectively). Therefore, increasing age significantly mitigated the prognostic importance of HCY as well as dimethylarginines as prognostic markers for long-term observations in our work. A strong influence of the variable age on these parameters via multivariate analyses could already be shown in multiple prior studies $[10,30]$. Therefore, the present study only assumed an influence on the results which finally remain to be proven. It is possible that the prognostic effect
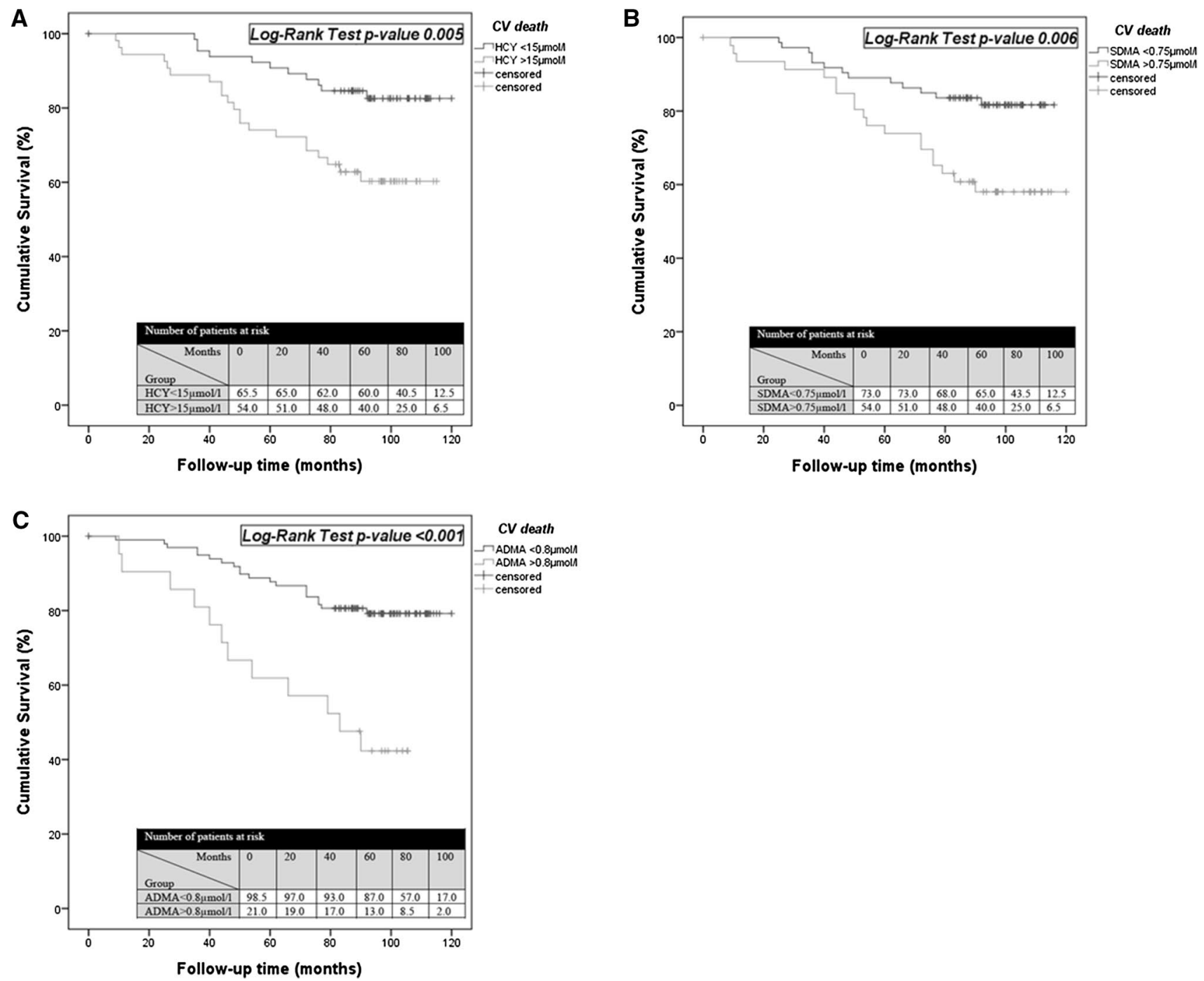

Fig. 2 Kaplan-Meier curves for survival of CV death between HCY $\leq />15 \mu \mathrm{mol} / 1$ (a), SDMA $\leq />0.75 \mu \mathrm{mol} / 1(\mathbf{b})$, and ADMA $\leq />0.8 \mu \mathrm{mol} / 1$ (c) 
Fig. 3 Correlation matrix between Age/eGFR/HCY/ SDMA/ADMA

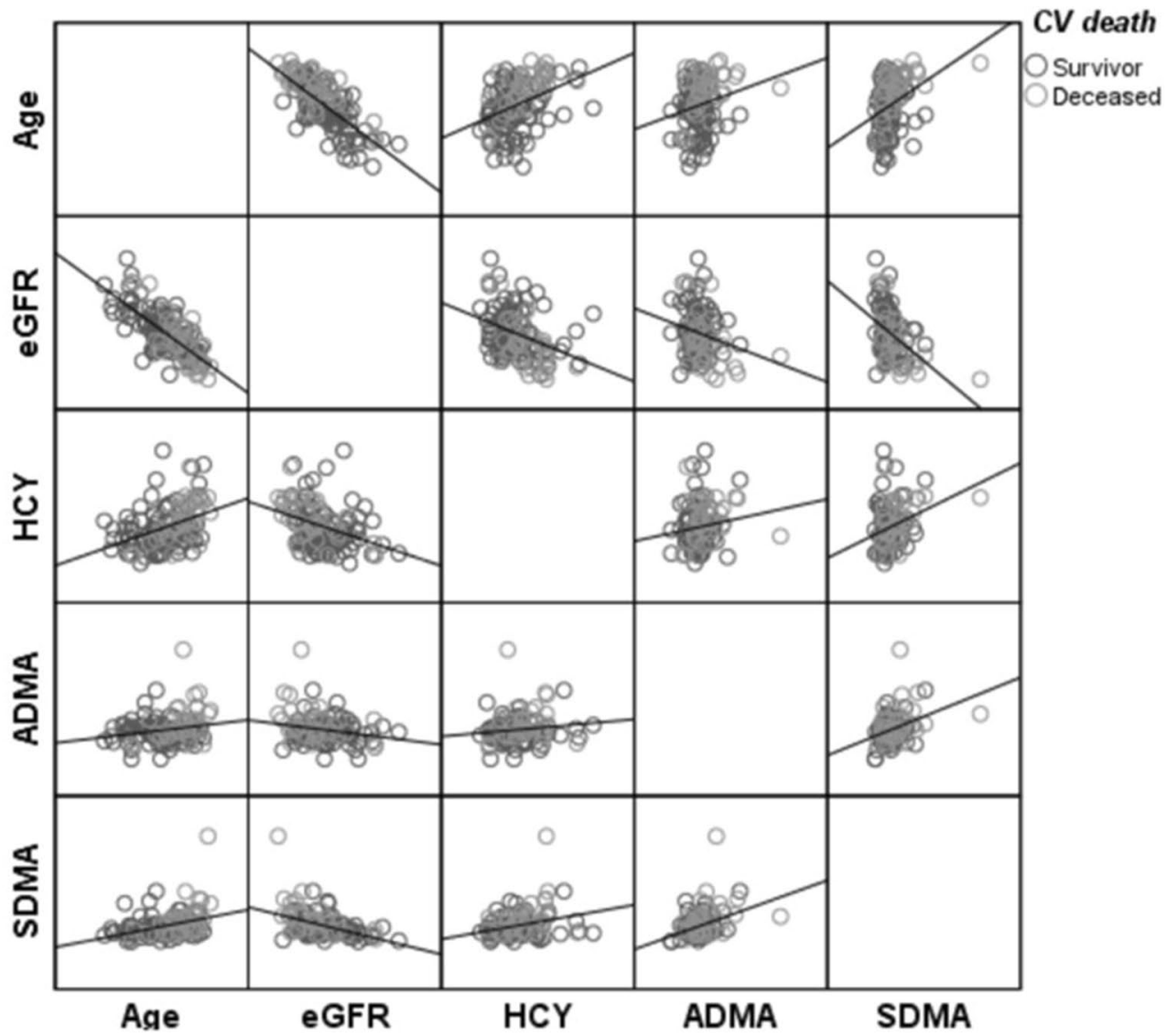

\begin{tabular}{|l|l|l|l|l|l|}
\hline Variable & Age & eGFR & HCY & ADMA & SDMA \\
\hline Age & & $\begin{array}{l}r=-0737 \\
p<0.001\end{array}$ & $\begin{array}{l}r=0.393 \\
p<0.001\end{array}$ & $\begin{array}{l}r=0.210 \\
p=0.021\end{array}$ & $\begin{array}{l}r=0.363 \\
p<0.001\end{array}$ \\
\hline eGFR & $\begin{array}{l}r=-0.737 \\
p<0.001\end{array}$ & & $\begin{array}{l}r=-0.369 \\
p<0.001\end{array}$ & $\begin{array}{l}r=-0.220 \\
p=0.016\end{array}$ & $\begin{array}{l}r=-0.451 \\
P<0.001\end{array}$ \\
\hline HCY & $\begin{array}{l}r=0.393 \\
p<0.001\end{array}$ & $\begin{array}{l}r=-0.369 \\
p<0.001\end{array}$ & & $\begin{array}{l}r=0.139 \\
p=0.130\end{array}$ & $\begin{array}{l}r=0.295 \\
p=0.001\end{array}$ \\
\hline ADMA & $\begin{array}{l}r=0.210 \\
p=0.021\end{array}$ & $\begin{array}{l}r=-0.220 \\
p=0.016\end{array}$ & $\begin{array}{l}r=0.139 \\
p=0.130\end{array}$ & & $\begin{array}{l}r=0.380 \\
\end{array}$ \\
\hline SDMA & $\begin{array}{l}r=0.363 \\
p<0.001\end{array}$ & $\begin{array}{l}r=-0.451 \\
p<0.001\end{array}$ & $\begin{array}{l}r=0.295 \\
p=0.001\end{array}$ & $\begin{array}{l}r=0.380 \\
p<0.001\end{array}$ & \\
\hline
\end{tabular}

of HCY, SDMA, and ADMA is overestimated in long-term observations especially as the strong association of these variables with $\mathrm{CV}$ events could also be explained by their significant age dependency. Therefore, we suggest that ageadjusted cutoff values for HCY and SDMA may estimate the risk for $\mathrm{CV}$ death more appropriately.

A limitation of our study is that it is one with a very selective patient cohort which investigated the mortality exactly for claudicant patients with Rutherford classification 2-3.
On the other hand, our overall patient cohort was rather homogenous regarding the dietary intake and prior exercise therapy. Therefore, these parameters should affect the HCY metabolism in a less distinctive manner in our study, and the HCY metabolism seems to be more depending on the age than on other conditions. Nevertheless, further evaluation with larger cohort studies including patients with other types of LEAD is necessary to clarify the age dependency 

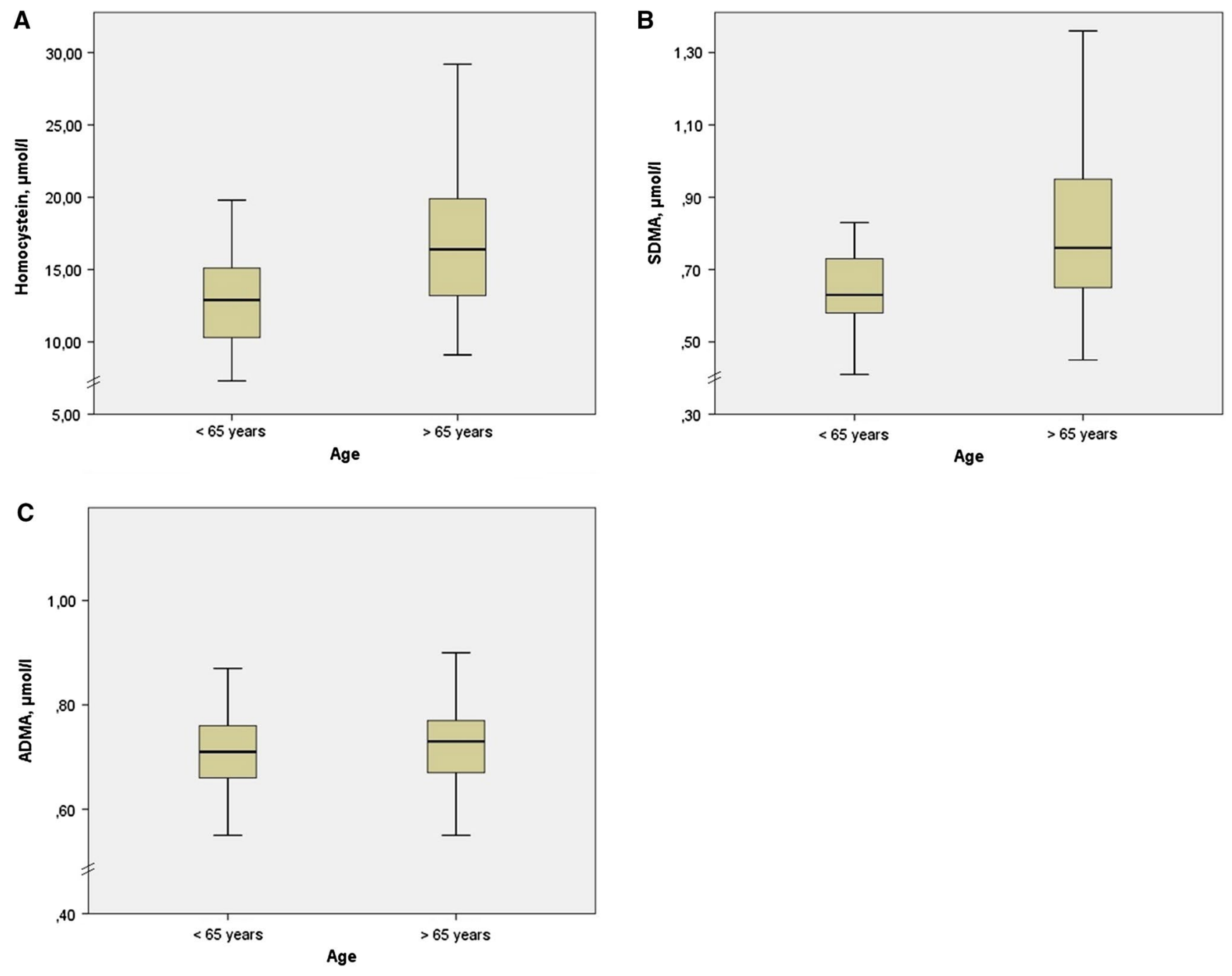

Fig. 4 Box plots for HCY (a), SDMA (b), and ADMA (c) concentrations between age cutoff $\leq />65$ years

of HCY, SDMA, and ADMA including their age-adjusted cutoff values.

\section{Conclusions}

In summary, the present study could prove a significant association between HCY and SDMA, but not between HCY and ADMA. Consequently, HCY-dependent endothelial dysfunction seems to be caused at least partially by dimethylarginines. Due to the distinct age dependency of HCY and SDMA in the present cohort, age-adjusted cutoff values for these parameters may be more appropriate as independent predictors of $\mathrm{CV}$ death.
Acknowledgements Open access funding provided by Medical University of Graz. We thank Anna Klambauer for proofreading and editorial assistance. All authors have read the journal's authorship agreement.

Funding This research received no specific grant from any funding agency.

\section{Compliance with ethical standards}

Conflict of interest All authors declare that no conflicts of interest exist.

Open Access This article is distributed under the terms of the Creative Commons Attribution 4.0 International License (http://creativeco mmons.org/licenses/by/4.0/), which permits unrestricted use, distribution, and reproduction in any medium, provided you give appropriate credit to the original author(s) and the source, provide a link to the Creative Commons license, and indicate if changes were made. 


\section{References}

1. Diehm C, Schuster A, Allenberg JR, Darius H, Haberl R, Lange S, Pittrow D, von Stritzky B, Tepohl G, Trampisch HJ (2004) High prevalence of peripheral arterial disease and co-morbidity in 6880 primary care patients: cross-sectional study. Atherosclerosis 172:95-105

2. Heitzer T, Schlinzig T, Krohn K, Meinertz T, Munzel T (2001) Endothelial dysfunction, oxidative stress, and risk of cardiovascular events in patients with coronary artery disease. Circulation 104:2673-2678

3. McCully KS (1969) Vascular pathology of homocysteinemia: implications for the pathogenesis of arteriosclerosis. Am J Pathol 56:111-128

4. Genest JJ Jr, McNamara JR, Salem DN, Wilson PW, Schaefer EJ, Malinow MR (1990) Plasma homocysteine levels in men with premature coronary artery disease. J Am Coll Cardiol 16:1114-1119

5. Michel T (2013) R is for arginine: metabolism of arginine takes off again, in new directions. Circulation 128:1400-1404

6. Schlesinger S, Sonntag SR, Lieb W, Maas R (2016) Asymmetric and symmetric dimethylarginine as risk markers for total mortality and cardiovascular outcomes: a systematic review and metaanalysis of prospective studies. PLoS ONE 11:e0165811

7. Weiss N, Heydrick SJ, Postea O, Keller C, Keaney JF Jr, Loscalzo J (2003) Influence of hyperhomocysteinemia on the cellular redox state-impact on homocysteine-induced endothelial dysfunction. Clin Chem Lab Med 41:1455-1461

8. Stuhlinger MC, Tsao PS, Her JH, Kimoto M, Balint RF, Cooke JP (2001) Homocysteine impairs the nitric oxide synthase pathway: role of asymmetric dimethylarginine. Circulation 104:2569-2575

9. Sydow K, Hornig B, Arakawa N, Bode-Böger SM, Tsikas D, Münzel T, Böger RH (2004) Endothelial dysfunction in patients with peripheral arterial disease and chronic hyperhomocysteinemia: potential role of ADMA. Vasc Med 9:93

10. Rasmussen K, Møller J, Lyngbak M, Pedersen AM, Dybkjaer L (1996) Age- and gender-specific reference intervals for total homocysteine and methylmalonic acid in plasma before and after vitamin supplementation. Clin Chem 42:630-636

11. Atzler D, Schwedhelm E, Nauck M, Ittermann T, Böger RH, Friedrich N (2014) Serum reference intervals of homoarginine, ADMA, and SDMA in the study of health in Pomerania. Clin Chem Lab Med 52:1835-1842

12. Riccioni G, Scotti L, D’Orazio N, Gallina S, Speziale G, Speranza L, Bucciarelli T (2014) ADMA/SDMA in elderly subjects with asymptomatic carotid atherosclerosis: values and site-specific association. Int J Mol Sci 15:6391-6398

13. Norgren L, Hiatt WR, Dormandy JA, Nehler MR, Harris KA, Fowkes FG, TASC II Working Group (2007) Inter-society consensus for the management of peripheral arterial disease (TASC II). J Vasc Surg 45(Suppl S):S5-67

14. Teerlink T, Nijveldt RJ, de Jong S, van Leeuwen PA (2002) Determination of arginine, asymmetric dimethylarginine, and symmetric dimethylarginine in human plasma and other biological samples by high-performance liquid chromatography. Anal Biochem 303:131-137

15. Meinitzer A, Puchinger M, Winklhofer-Roob BM, Rock E, Ribalta J, Roob JM, Sundl I, Halwachs-Baumann G, März W (2007) Reference values for plasma concentrations of asymmetrical dimethylarginine (ADMA) and other arginine metabolites in men after validation of a chromatographic method. Clin Chim Acta 384:141-148

16. Hustad S, Eussen S, Midttun $\varnothing$, Ulvik A, van de Kant PM, Mørkrid L, Gislefoss R, Ueland PM (2012) Kinetic modeling of storage effects on biomarkers related to $\mathrm{B}$ vitamin status and one carbon metabolism. Clin Chem 58:402-410

17. Hankey GJ, Eikelboom JW (1999) Homocysteine and vascular disease. Lancet 354:407-413

18. Fanapour PC, Yug B, Kochar MS (1999) Homocysteinemia: an additional cardiovascular risk factor. WMJ 98:51-54

19. Carmody BJ, Arora S, Avena R, Cosby K, Sidawy AN (1999) Folic acid inhibits homocysteine-induced proliferation of human arterial smooth muscle cells. J Vasc Surg 30:1121-1128

20. Chao CL, Chien KL, Lee YT (1999) Effect of short-term vitamin (folic acid, vitamins B6 and B12) administration on endothelial dysfunction induced by post-methionine load hyperhomocysteinemia. Am J Cardiol 84:1359-1361

21. Tawakol A, Omland T, Gerhard M, Wu JT, Creager MA (1997) Hyperhomocyst(e)inemia is associated with impaired endothelium-dependent vasodilation in humans. Circulation 95:1119-1121

22. Kiechl S, Lee T, Santer P, Thompson G, Tsimikas S, Egger G, Holt DW, Willeit J, Xu Q, Mayr M (2009) Asymmetric and symmetric dimethylarginines are of similar predictive value for cardiovascular risk in the general population. Atherosclerosis 205:261-265

23. Schulze F, Carter AM, Schwedhelm E, Ajjan R, Maas R, von Holten RA, Atzler D, Grant PJ, Böger RH (2010) Symmetric dimethylarginine predicts all-cause mortality following ischemic stroke. Atherosclerosis 208:518-523

24. Schwedhelm E, Wallaschofski H, Atzler D, Dörr M, Nauck M, Völker U, Kroemer HK, Völzke H, Böger RH, Friedrich N (2014) Incidence of all-cause and cardiovascular mortality predicted by symmetric dimethylarginine in the population-based study of health in pomerania. PLoS ONE 9:e96875

25. Li H, Horke S, Förstermann U (2014) Vascular oxidative stress, nitric oxide and atherosclerosis. Atherosclerosis 237:208-219

26. Chung HY, Sung B, Jung KJ, Zou Y, Yu BP (2006) The molecular inflammatory process in aging. Antioxid Redox Signal 8:572-581

27. Liu LH, Guo Z, Feng M, Wu ZZ, He ZM, Xiong Y (2012) Protection of DDAH2 overexpression against homocysteine-induced impairments of DDAH/ADMA/NOS/NO pathway in endothelial cells. Cell Physiol Biochem 30:1413-1422

28. Palm F, Onozato ML, Luo Z, Wilcox CS (2007) Dimethylarginine dimethylaminohydrolase (DDAH): expression, regulation, and function in the cardiovascular and renal systems. Am J Physiol Heart Circ Physiol 293:H3227-3245

29. Trocha M, Merwid-Ląd A, Chlebda-Sieragowska E, Szuba A Pieśniewska M, Fereniec-Gołębiewska L, Kwiatkowska J, Szeląg A, Sozański T (2014) Age-related changes in ADMA-DDAHNO pathway in rat liver subjected to partial ischemia followed by global reperfusion. Exp Gerontol 50:45-51

30. Schwedhelm E, Xanthakis V, Maas R, Sullivan LM, Schulze F, Riederer U, Benndorf RA, Böger RH, Vasan RS (2009) Asymmetric dimethylarginine reference intervals determined with liquid chromatography-tandem mass spectrometry: results from the Framingham offspring cohort. Clin Chem 55:1539-1545 